Vol 41 (2016) No 184 169-191

\title{
Multicultural Education: The Challenges and Attitudes of Undergraduate Students in Turkey
}

\author{
Hamdi Alanay ${ }^{1}$, Hasan Aydın ${ }^{2}$
}

\begin{abstract}
Multicultural education is a process that attaches importance to the differences between students and makes no attempt to deny their existence. This ensures that the process continues in an egalitarian manner. Multicultural education is an educational reform movement that exists within the context of a wider process of societal reform and supports the principle that no inequality of educational opportunity should exist on account of differences of race, ethnicity, identity or social class. The purpose of this study is to identify the views of undergraduate students concerning multicultural education. In this regard, the attitudes of undergraduate students at school of education were examined to see if there existed significant differences in their views taking the moderating variables of the students' gender, ethnic identity, type of university (private or state) and type of department into account. In this study, a quantitative research method was used, employing the Mann Whitney U Test and Kruskal Wallis H Test analysis within the analysis process. A scale was developed to collect data for the study. The scale was divided into 3 different factors or categories. These were defined as the results of multicultural education, the effect of university education on multicultural education, and education and justice. The results of this study indicated that college students' responses on multicultural education were largely positive.
\end{abstract}

Keywords

DOI: 10.15390/EB.2016.6146

\section{Introduction}

Multicultural education has been described as a structural change within the educational system (Banks, 1999; Gay, 2004). Banks in his description, that went on to describe the concept in full, emphasized multicultural education as one (form of education) that endeavored to raise individuals distant from stereotyped ethnic judgements and discrimination(s) and that supported the cultural richness of the society while simultaneously giving value to it. In addition, Aydin (2013a) argues that multicultural educat, on is an educational reform that is designed with the aim of bringing about deeprooted transformations with regard to the role and position of students within the educational system. Theoreticians and researchers of multicultural education in their studies concerning the racial and ethnic origins (of students) at numerous schools, colleges and universities have come to believe that

\footnotetext{
${ }^{1}$ Doctoral student at Marmara University, Istanbul, Turkey, hamdialanay@gmail.com

2 Yildiz Technical University, School of Education, Multicultural Education, Curriculum and Insturction Department, Turkey, aydinh@yildiz.edu.tr
} 
embedded ethnic and discriminatory stereotypes predominate that are to the detriment of students (Aydin, 2012; Banks, 2008, Gay, 2004). Multicultural education assumes that race, ethnic origin culture and social class represent distinct elements of American society. Simultaneously, ethnic and cultural diversity enriches the nation and raises the ability to perceive and solve personal problems. At the same time, by increasing the opportunities for all citizens to gain experiences of other cultures, it ensures that humanity as a whole becomes both more experienced and satisfied in its dealings with others (Banks, 1999).

In addition, Gorski (2006), by including the aspects mentioned above and combining them with the findings presented by scholars including Banks (2004a), Grant and Sleeter (2006), Sleeter (1996) and Nieto (2004), defined the five principal characteristics of multicultural education as follows:

1. Multicultural education is a political and social movement and a process that attempts to bring about the security of social justice for both individuals and society without making distinctions for race or ethnic background, sexuality, mother tongue, physical disability (or lack of it), social-econmoic status and/or any perceived individual or group identity.

2. Multicultural education, while being related and connected with certain elements of multicultural education present within authentic forms of educational systems, is a phenomenon of social justice (guaranteed constitutionally) and may only be protected through educational reforms.

3. Multicultural eduction, it should be stressed, may only succeed through a school reform that conducts a critical analysis of the strengths and priorities of existing educational systems.

4. Only fundamental and critical analyses of the goals of education may lead to a reduction in the inequalities of education.

5. Multicultural education represents a quality and positive education for all students.

Multicultural education is a concept that has been developed to remove the difficulties and inequalities experienced on account of cultural differences by in essence allowing students to take advantage of equal opportunities and possibilities in a democratic environment. On account of the fact that the cultural problems of every society and different and varied, there exist a number of descriptions regarding multiculturalism. According to Aydin (2013b), multicultural education is an approach that attaches importance to differences and contrasts in the classroom environment. Gay (1994) instead described multicultural education as a process that necessitates the creation of educational institutions that both in their structure and form guarantee that students may obtain equal opportunities and academic success. Polat and Kilic (2013) regarded multicultural education as an educational movement that existed with a 'single face' that contained within it the principles of equal rights and was sensitive to it, was attentive to these principles and that remained respectful towards those who thought and lived differently and to other cultures; this does not mean merely attention to the individuals with different cultures that existed within the system (Ergil, 1995, p. 160). In this sense, multicultural education may be explained as being a system that rather than rendering people distinct on account of their differences, accepts them, and indeed sees them as an inherent source of richness, so as to create individuals who are thinking, inquisitive and able to make criticisms of their own cultures. Parekh (2002) defined those societies in which two or more cultures live together as being multicultural societies. 
Changes in the demographics of the nation and the influx of Syrian refugees into schools and the workplace have resulted in a need to change the way that students are taught. Results of this study can help educators, scholars, and policy-makers to understand how students perceive multiculturalism and if these perceptions are developmental. Woods (2009) also argues that "teachers and administrators who are responsible for helping students understand the importance of harmony in the school can begin to understand how students' perceptions of multiculturalism influence their behaviors and actions with other students" (p. 12). By teaching mutual respect and understanding for similarities and differences among diverse cultures within a school, students can be better prepared to take their place in a global society that requires them to work alongside of and be neighbors to people who have different beliefs and habits from their own (Aydin \& Tonbuloglu, 2014; Kaya, 2015; Karatas \& Oral, 2015; Woods, 2009). When we consider the example of Turkey, we can regard it as a culture of societies or communities that have grown up within the context of the Ottoman Empire. After the foundation of the Turkish Republic that was founded on the concept of the single nation model, there was a sustained attempt to obstruct cultural rights including the prevention of the use of different (ethnic) languages (Kaya, 2015; Kaya \& Aydin, 2014). These obstructions of and deprivation of cultural rights, led to feelings of inequality among different cultural groups and led to situations in which they were not able to meet on equal terms in a shared social space. For this reason the reduction of culture to a single standard, rejected the existence of cultural diversity.

In recent years, when one considers the demands and suggestions suggested in view of attempts to find solutions and consensus with regard to the ethnic and cultural problems existing in Turkey, one finds a number of cultural rights being requested. Education in the students' mother tongue language still represents the issue of priority (of cultural groups) (Kaya, 2007). According to the UKAM (2013a) report, at the top of the list of problems is recognition of the right to education in one's mother tongue language. In this context, the recognition of a large number of rights regarding native language education and the reaching of clarification concerning this issue with the view to reducing immediate problems may be seen as essential steps in this process (Faltis, 2014).

Multicultural education emphasizes the need to create a society in which universal and democratic rights are at the forefront and respect is shown towards different cultures present within that society (Kaya, 2014; Lafer, 2014). In this regard, Bulut (2015) argued that the empathy and creative skills of students should be increased, importance should be attached to the feelings of others and the abilities of students to put themselves in the place of others. In such a way, students will not only remain focused on their own country, but will instead reach a state in which they become more open to the world and attain a sense of universality. Parekh (2002, p. 286) summarizes the values that students will gain through multicultural society as follows:

- The creation of a culture comprising of numerous cultures,

- The increase in communication between cultures. The ability to take advantage of mutual cultural values

- Rather than remaining focused on one source (of knowledge) or one trend, experiences and practices are obtained from all over the world.

- On account of multicultural education, students abandon any prejudices and racist thoughts.

The learning objectives of students within the context of multicultural education are listed above. In order to reach these learning objectives, an appropriate educational program must first be prepared. Values within existing educational programs that are based on the concept of the single nation need to be highlighted (for examination). For example, in many systems, white men originating from Europe are seen as being responsible for all achievements. Instead, space should be allocated to incorporate the values of different cultures and races (Cotok, 2010). In this way, while the achievements of different cultures may be explained, the content may be used to incorporate concepts such as freedom and equality. 


\section{Models of Multicultural Education}

The basis of multicultural education, as defined by Banks (1995) is the creation of beliefs that all students have a right to learn, all students should be given the same opportunity of learning and that these targets are attainable through a process of constant reform and change (aiming towards these goals). Banks's (1995) effective model of multicultural education includes five princpal elements. First, multicultural education supports the integration of multicultural educational contact and requires diversity of program materials. Second, there is a need to examine the construction of knowledge and from a (theoretical) viewpoint to show how knowledge is formed and how people obtain results (through the learning process). Third, there should be an attempt to reduce prejudice by showing the positive aspects of different groups. Fourth, by using different learning and teaching approaches, there should be an attempt to arrive at a 'just' style of teaching. Finally, multicultural education brings about alterations to the school environment and make-up of the institution, and ensures the provision of positive school atmosphere that allows students to mix with one another.

Kitano (1997) based his thoughts derived from threse ideas to describe the three types of lesson that should be contained within a multicultural approach; he entitled these 'the non-exclusive', 'comprehensive' and 'transformed' lesson. The non-exclusive lesson was defined as one in which history and knowledge was described as one using embedded or stereotyped expressions, in which the presentation of different cultures was included, but the presentation of the lesson was in essence traditional. A comprehensive lesson was one in which the general trends and traditional viewpoints on a topic were presented, however, additional points of view were also added. A 'transformed' lesson is one in which accepted traditions are challenged, new concepts and ways of thinking are creating and an exchange of power takes place between the educator and the students. The content of a transformed lesson changes as regards subject content, teaching strategies, in-class activities, evaluations and class dynamics. With their definitions of transformative multicultural education, Kitano (1997) and Banks (1995) argued that the success of multicultural education required going beyond a simple change in attitude.

\section{Criticisms of Multicultural Education}

In addition to studies that have emphasized the positive and necessary aspects of multicultural education, a number of prejudices and criticisms have also been expressed with respect to the topic. These criticisms mainly emanate from the lack of sufficient information concerning multicultural education. In addition, there have been a number of negative viewpoints expressed with regard to worries that multicultural education harbors malevolent intentions that serve to increase the distance between different groups and to damage the unity and territorial integrity of the nation state. According to Bennett (1995), the excessive highlighting of cultural differences may lead to situations in which negative reactions are displayed towards cultural differences and students experience condescension because of their cultural experiences. For instance, multicultural education may be seen as a component that has simply been added to existing education programs to placate those of an African background, Latinos, Far-east Asians, East Asians and those of other minority groups or for women (Glassman, Swatos, \& Denison, 2004, p. 267).

Multicultural education is not merely a form of education aimed at men and women, black and white people or any special group. Multicultural education is an educational movement that encompasses all students and that ignores cultural differences with the view of ensuring that every individual becomes an active citizen (Karatas \& Oral, 2015). The greatest mistake made in this regard is the thought that multicultural education is the provision of rights within education so as to enable certain groups to exercise specific cultural rights (Glazer, 1997). This erroneous understanding revealed a thinking that multicultural education was a system 'designed' for others. Certain opponents of multicultural education evaluated the system in terms of an Africa-centered form of education and therefore it was an application that was to be put into practice for others (Banks \& Banks, 2013). Whereas, multicultural education, on reaching a point in which it embraces all groups is an educational movement that can be applied by everyone in schools that have accepted its principles (Banks \& Banks, 2013). Another criticism connected with multicultural education is the worry that the system will serve 
to divide the country. It has created the idea that the awarding of certain rights to different ethnic, racial and cultural groups living in the same country will damage the territorial integrity and indivisibility of the country and lead to a change in the geographical borders of the country.

\section{The Multicultural Educational Program}

The effect of the teacher and the school environment within the multicultural environment is very pronounced. According to Gay (2002), in addition to attaining knowledge about other cultures, teachers must learn how to design programs according to multicultural educational principles and learn know how to change the way students (think and behave) through adaptations in their style of lesson delivery. Furthermore, so as to respond to the cultural diversity of the society incorporated within the educational program, he must act within a spirit of effort and endeavor to apply and transform the findings of academics at college of education and studies conducted by them into a form appropriate for implementation within a multicultural educational school setting (Brown, 2007).

The expert in multicultural education, Banks (2004b) has outlined the four stages that may be employed in the adaptation of school programs to multicultural education

1. The Contributional Approach: In this approach, themes that bring attention to the culture such as special days, activities and traditions pertaining to that culture, and important people, types of food and music that have formed an impression (on other cultures) may be expressed in a superficial way.

2. The Additional Approach: In this approach, the structure of the original program is not altered; however, certain content elements, concepts, themes and viewpoints may be added.

3. The Transformative Approach: In this approach, the structure of the program may be changed. Students are assisted in seeing concepts, topics, themes and problems from the points of view of other groups.

4. Social Action Approach: In this approach, students make decisions about social topics and develop actions to realize solutions.

Kridel (2010) stressed the fact that during the creation of the program, attention should be paid to developing a learning strategy that was egalitarian and appropriate for the students of different cultural groups. In cases where such sensitivity is displayed, it was argued that the programs would affect students' development so as to ensure success from a social, psychological and academic perspective and accelerate their learning process in a positive direction.

Another prominent researcher in the field of multicultural education, Cirik (2008) rather than conveying multicultural education as a section or area within an existing program, indicated that it was more beneficial to regard multicultural education as a field in which the existing program is recreated through a redefinition of its internal stages, namely the targets, contents and evaluation. In a definition offered by Bennett (1995) to support this approach, he argued the program and other factors must be combined so as to realize the goals of multicultural education. Bennett argued that the necessary elements for a successful multicultural educational program were the positive expectations of the teacher, support between cultures and the competence of administrators and teachers. Schmitz (1999), for his part, listed the principles that ought to be employed in the preparation of a multicultural educational program as follows:

1. Attention to the sociological structure of society when defining learning targets.

2. Attention attached to an Examination of Traditional Concepts.

3. Attention to Differences among students.

4. Attention to the determination and choice of materials and activities.

5. When considering multicultural education within the the stages of evaluation, of the type of evaluation to be conducted should be taken into account.

In this context, the purpose this study is to identify the viewpoints of undergraduate students at universities in Istanbul with regard to multicultural education. Within the scope of the study, differences in opinions were examined from the perspective of the following differentiating factors: 
gender, ethnic identity, type of university (private/state) and department (at which the students were enrolled). With this aim in mind, there was an attempt to find answers to the following questions:

- What are the views of undergraduate students at the educational faculties of universities situated in Istanbul with regard to multicultural education?

- Is there a significant difference in viewpoints toward multicultural education with regard to the gender of participants?

- Is there a difference in viewpoints towards multicultural education with regard to the ethnic background of the participant and/or how he or she described it?

- Is there a difference in the opinions of students regarding multicultural education according to the type of university they attended (private or state university)?

- Is there a difference in the viewpoint towards multicultural education with regard to the department at which they study?

\section{Methodology}

\section{Research Design}

This study employed a quantitative methodological approach, consisted of a descriptive Likertscale survey to better understand the attitudes of undergraduate students' view points on multicultural education in Turkey. Descriptive methods are employed to define the position of the problem that is desired to be researched within an existing situation. In this method, the present situation is studies within its own conditions (Sonmez \& Alacapinar, 2011). Within the scope of this study, a scale prepared for the preliminary test was sent to 240 participants and an descriptive factor analysis was carried out. With the view to confirming the factors that emerged from this analysis, the scale to measure views was sent again impartially to 221 participants and confirmatory factor analysis was carried out. Factors that constituted the criteria of measurement were rearranged in accordance with the reliability analysis. The scale that was completed in accordance with its content and structural validity was then sent to the participants so as to gather actual data.

\section{Participants}

The participants of this study covers undergraduate students in school of education at both one private and four state universities in city of Istanbul. The target population of this study was consisted 6400 undergraduate students and data collection process, informed information sheet forms along with the data collection tool, however, only 967 volunteer students completed the survey. The participants consisted 761 were female $(78.69 \%)$ and $206(20.30 \%)$ were male. Researchers perceived that female students participated more and volunteered responses more frequently than male students. In the study, a purposive sampling was used with the aim of constituting a sample that would be best represented the characteristics of undergraduate students who participated in this study. In this method, the size of the sample is defined and the chosen sample application is then carried out (Buyukozturk, Kilic Cakmak, Akgun, Karadeniz, \& Demirel, 2014).

The scale address was then sent to students at the college of education via e-mail. A total of 1050 students at college of education took part in the study. However, data from a total of 83 scale that did not fit the context of the study or that were not fully completed were not included in the evaluation process.

Table 1. Distribution According to University

\begin{tabular}{lll}
\hline & Percentage (\%) & Frequency (f) \\
\hline Private & 36,19 & 350 \\
State & 63,81 & 617 \\
Total & 100 & 967 \\
\hline
\end{tabular}

In Table 2, the rates of participation of those (students) from private and state universities can be examined. While $36.2 \%$ of the participants consisted of students who attended private universities, the remaining $63.8 \%$ was made up of those from state universities. 
Table 2. Distribution According to Department

\begin{tabular}{lll}
\hline & Percentage (\%) & Frequency (f) \\
\hline Computer Education Instructional Technologies (CEIT) & 11,69 & 113 \\
Religious Culture and Moral Instruction Teaching & 2,79 & 27 \\
Science Teaching & 12,00 & 116 \\
Mathematics Teaching for Primary & 15,31 & 148 \\
Mathematics Teaching & 3,10 & 30 \\
Pre-School Teaching & 14,17 & 137 \\
Psychological Consultancy and Guidance & 14,17 & 137 \\
Elementary Teacher Training & 0,83 & 8 \\
Humanities Teaching & 7,55 & 73 \\
Turkish Language Teaching & 0,93 & 9 \\
Foreign Languages Teaching & 10,44 & 101 \\
(Not stated) & 4,55 & 44 \\
(Other) & 2,48 & 24 \\
(Total) & 100 & 967 \\
\hline
\end{tabular}

In Table 2, the distribution of participants in the scale according to the department at which they studied is indicated. According to this make up, the departments that constituted the largest number of participants were the Computer Education Instructional Technologies, Primary Mathematics Teaching, Science Teaching, Preschool Teaching, Psychological Counseling and Guidance (PCG) and Foreign Language(s) Teaching departments.

\section{Data Collection}

On examination of the academic literature in the view, the researchers did not come across a tool of measurement that would serve to identify the views of undergraduate students with regard to multicultural education. This scale was developed with great endeavor and effort so as to address the needs of the researchers and study as well as to provide a tool of measurement for future studies in the field literature.

A Scale for the Measurement of Multicultural Education of Undergraduate Students (SMMEUSCE) at the College of Education and its characteristics

The scale to measure Multicultural Education of Undergraduate Students at the Faculty of Education, before specifying the technical features (validity and reliability), was formatted in three sections. The first section was prepared to define the demographic properties of the study. In this section, eight questions regarding demographic properties (gender, age, income level etc) were asked. In the second section, nine questions were asked that aimed to elicit opinions about multicultural education. To elicit as many as opinions as possible nine questions were asked with five choices for each and multiple-answers to the same question were allowed. In the third section, 19 statements that attempted to determine the perceptions of undergraduate students at college of education were formatted. A choice of answers modeled on the Likert scale (definitely do not agree, do not agree, partly agree, agree and definitely agree) was also created. 
Before developing the questionnaire, the researchers conducted a detailed literature review on the topic of multicultural literature. The scale that was created in light of the references taken from the literature, were then shown to experts in the field so as to elicit their opinion before including it within the application of the experiment. In this regard, the scale was sent to experts from the four main branches of educational sciences, all of whom had conducted research on the topic of multicultural education. Scholars were allowed a two-week period to present their opinions and to allow them to make comments on the items and statements included in the scale as well as to indicate deficiencies in the questionnaire. In light of the comments and feedback issued, two other academicians currently studying at doctorate level in the field of assessment and evaluation also assisted in revising the questionnaire. On examining the correlation values of the questionnaire, they were found to be consistent to a high degree. In this respect, a consensus of opinion/general agreement was reached. In line with the feedback received from experts in the field, a final version of the scale was created and an experimental application was devised.

From the 19-statement section measuring perceptions that was included at the end of the application, two statements (22 and 26) displayed a low correlation, while two statements showed a weighting in more than one factor. These items were then removed from the questionnaire. As a result of this process, 15 items remained. The remaining 15 items were then renumbered.

The remaining 15 items in the scale were then collected under three main factors. The names of these factors and items included under these categories are shown below:

- Results of Multicultural Education (RME): This category shows perceptions with regards to situations that emerge as a result of attaching importance to multicultural education. This factor/area consists of statements 10,11,12,13,14,15 and 16. The highest score that may be obtained is 35. A high score indicates that multicultural education leads to positive results.

- The Effect of University Education on Multicultural Education (EUEME): This demonstrates the perceptions of participants with regard to the multiculturalism of lessons taken at university and the effect of multicultural education. This factor consists of statements17,18, 19, 20 and 21. The highest score that can be obtained is 25. A high score indicates the positive effect of university lessons on multicultural education.

- Equality and Justice (EJ): This factor reflects the perceptions of equality and justice within the context of multicultural education. This factor consists of statements 22, 23 and 24. The highest score that a participant may obtain is 15. A high score indicates perceptions of equality and justice.

Items 14 and 22 on account of perceived bias or negative meaning were codified in reverse.

\section{Findings from Explanatory Factor Analysis Data}

The data were uploaded into IBM-SPSS 21 software. Explanatory factor analysis is a type of analysis that is used with the aim of revealing the factorial structure of data with the view to demonstrating what kind of scale or scale is needed to define associated properties or characteristics included within the data. On account of the fact that between 10 and 28 questions indicated questionnaire-style properties, principal components analysis was conducted on the data set obtained from 240 individuals within the context of the explanatory factor analysis. Before proceeding to the analysis stage, it is considered whether the content of the data set is appropriate to be exposed to factor analysis; in short it is necessart to conduct Kaiser Meyer Olkin (KMO) and Bartlett tests to establish the suitabilitity of the data test (Buyukozturk, 2003; Ozdamar, 2013). The KMO value of the analysis was found to be 0.8333 . When this value stands at above 0.50 , this indicates the suitability of the data set for exposure to factor analysis. The result of the Bartlett Test was as follows: $\left(X^{2}=1374.363 ; \mathrm{sd}=105, \mathrm{p}<0.01\right)$ The fact that this value was significant indicates that factor analysis could be successfully conducted.

On account of the fact that according to the 19 question scale devised, questions number 22 and 26 were below the total correlation of items and items 12 and 14 were found to show a high correlation 
in one or two factors ; these were removed from the questionnaire. The remaining 15 items indicated a structure of three main factors. The weighted factor values with regard to the remaining 15 items, the total correlations of the items, the properties related to the three-factor scale (attitudes to multicultural education).

Table 3. Loaded Values of Primary Factors in the Factor Analysis and the Overall Correlation Results of Items

\begin{tabular}{llllll}
\hline Item No. & $\begin{array}{l}\text { Loaded Value of } \\
\text { Primary Factor }\end{array}$ & $\begin{array}{l}\text { Item-Total } \\
\text { Correlation }\end{array}$ & Item No. & $\begin{array}{l}\text { Loaded Value of } \\
\text { Primary Factor }\end{array}$ & $\begin{array}{l}\text { Item-Total } \\
\text { Correlation }\end{array}$ \\
\hline $\mathbf{I 1 0}$ & 0.58 & 0.57 & $\mathbf{I 2 0}$ & 0.26 & 0.33 \\
$\mathbf{I 1 1}$ & 0.54 & 0.58 & $\mathbf{I} 21$ & 0.60 & 0.45 \\
$\mathbf{I 1 3}$ & 0.59 & 0.59 & $\mathbf{I} 23$ & 0.79 & 0.55 \\
$\mathbf{I 1 5}$ & 0.55 & 0.31 & $\mathbf{I 2 4}$ & 0.84 & 0.51 \\
$\mathbf{I 1 6}$ & 0.37 & 0.43 & $\mathbf{I} 25$ & 0.51 & 0.37 \\
$\mathbf{I 1 7}$ & 0.53 & 0.52 & $\mathbf{I 2 7}$ & 0.57 & 0.50 \\
$\mathbf{I 1 8}$ & 0.64 & 0.51 & $\mathbf{I 2 8}$ & 0.59 & 0.36 \\
$\mathbf{I 1 9}$ & 0.57 & 0.40 & & & \\
\hline
\end{tabular}

Variation between the four factors $56.86 \%$

Cronbach Alpha $=0.83$

On examination of table 3, it can be observed that the primary loaded values of the items vary between 0.26 and 0.84 . The correlations between the item and the total range from 0.31 to 0.59 . Within the scope of this study Cronbach's Alpha internal consistency coefficients were recalculated to validate re-measurement reliability of multicultural education. The measurement of the remaining items, namely the variation in attitudes towards multicultural education is given as $56.86 \%$. The Cronbach Alpha internal coefficient of efficiency with regard to reliability when the scale is taken to be onedimensional is stated as 0.83 . In such a situation, the coefficient relating to the reliability of all items may be described as high (Buyukozturk, 2003; Ozdamar, 2013).

Principal component analysis indicates whether there are sub-values on the scale devised. In order to determine reliably the sub values, a revolving method was applied to data obtained from 240 individuals (Buyukozturk, 2003; Ozdamar, 2013).

Table 4: Factors derived as a result of Varimax (revolving data analysis) and items placed under each factor

\begin{tabular}{lllc}
\hline Items & \multicolumn{3}{c}{ Factors/Areas } \\
\cline { 2 - 4 } & $\mathbf{1}$ & $\mathbf{2}$ & $\mathbf{3}$ \\
\hline $\mathbf{I 2 7}$ &, 750 & & \\
I10 &, 733 & & \\
I28 &, 703 & & \\
I13 &, 693 & & \\
I11 &, 673 & & \\
I18 &, 604 & & \\
I16 &, 539 & & \\
I24 & &, 902 & \\
I23 & &, 858 & \\
I21 & &, 762 & \\
I25 & &, 705 & \\
I20 & &, 482 & \\
I15 & & & \\
I19 & & & \\
I17 & & & \\
\hline
\end{tabular}


Table 4 indicates that items 10,11, 13, 16, 18, 27 and 28 formed a pattern. On observing the items that made up this pattern, it was decided that the pattern or area analyzed could be given the name. It was also established that items 20,21, 23, 24 and 25 also constituted another pattern. It was decided that this category could be named "the Effect of University Education on Multicultural Education (EUEME)". Items 15, 17 and 19 were also seen to constitute another shape or pattern. This pattern or category was given the title "Equality and Justice (EJ)".

1.

The patterns formed can be examined visually in the figure displayed on the Scree Plot in Figure

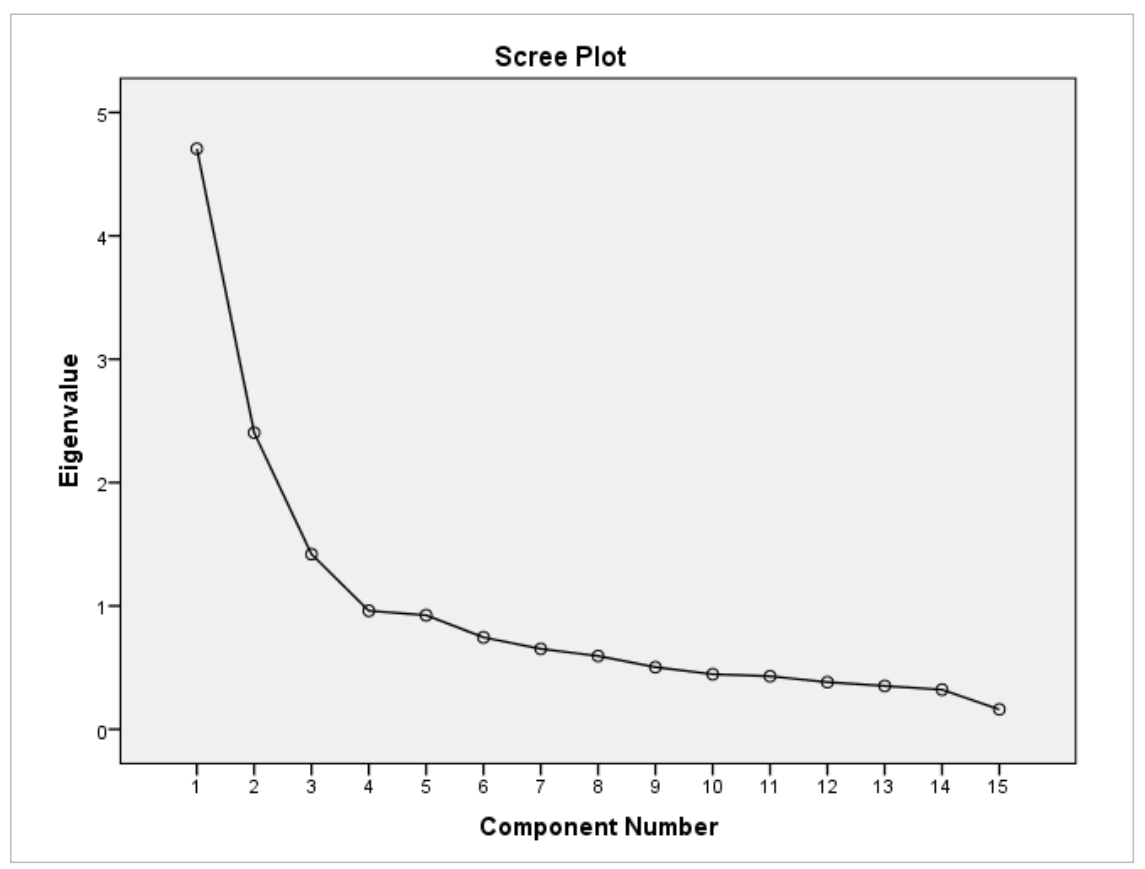

Figure 1: A Scree Plot Visualization of the Subdimensions of the Section Illustration of Factors on a 15Item Scale

On the Scree Plot it can be seen that after the first three components, the factors gradually level out. This image may be regarded as evidence of a scale consisting of three dimensions.

\section{Findings from the Confirmatory Factor Analysis}

With view to establishing whether the structure of the scale emerged in accordance with the results of the confirmatory factor analysis, factor analysis was conducted with the aid of IBM-AMOS software on the date set obtained from 221 individual participants. The model that emerged as a result of this analysis can be seen in Figure 2. 


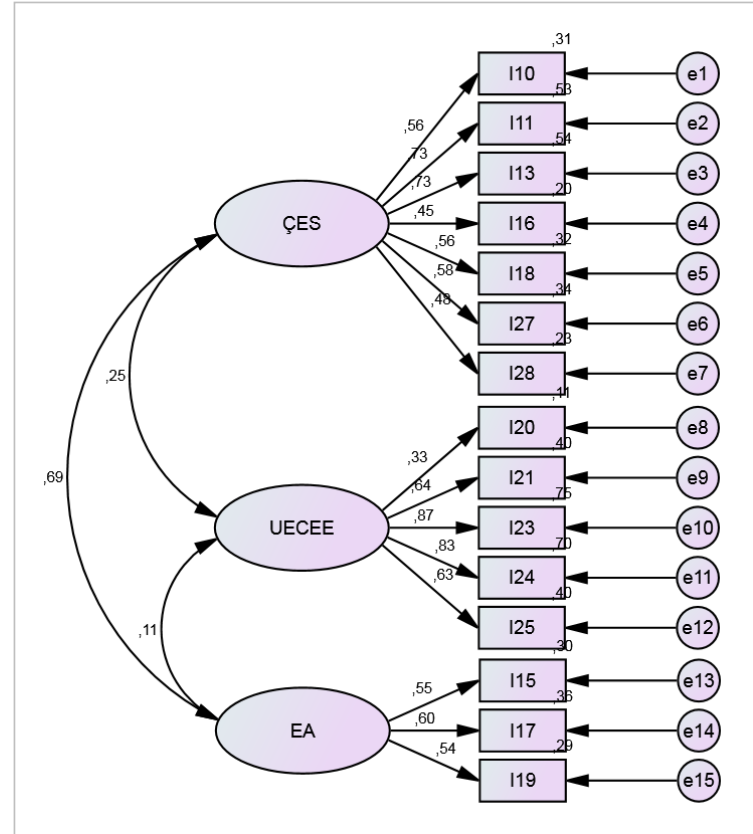

Figure 2: A Factor-Analysis Diagram concerning the lower values of the section showing the common scale properties of items

The fit indices obtained as a result of the Confirmatory Factors Analysis.

Table 5. Fit Indices from the Confirmatory Factor Analysis

\begin{tabular}{ll}
\hline Fit Index & Value \\
\hline Chi-square $\left(X^{2}\right)$ & 270.15 \\
Degree of Freedom (sd) & 98 \\
$X^{2} /$ sd & 2.75 \\
Goodness of Fit Index (GFI) & 0.86 \\
Adjusted Goodness of Fit Index (AGFI) & 0.81 \\
Root Mean Square Error of Approximation (RMSEA) & 0.08 \\
Root Mean Square Residual (RMR) & 0.08 \\
\hline
\end{tabular}

As a result of the confirmatory factor analysis the chi square and the degree of freedom values are seen to be $X^{2}=270.15$, $(\mathrm{sd}=98, \mathrm{p}<.01)$ with a ratio of $X^{2} / \mathrm{sd}=2.75$. The fact that the rate obtained from the sample was found to be below 3, this indicates perfect harmony (Joreskog \& Sorbom, 1993; Kline, 2005; Sumer, 2000). It can be stated that the harmony between the model that resulted from the confirmatory factor analysis conducted in this research and the data obtained can be seen to fit each other perfectly.

In cases where the GFI values of the factor model are found to be close to (a value of) 1 , this explains that the data under observation is at a very high level and indicates the suitability of the model Where the GFI is higher than 0.70 , the original variability of the factor model is seen to have been sufficiently accounted for, and indicates the model can be used, is suitable and is a good model (Ozdamar, 2013). In cases when the GFI is equal to or higher than this values, one speaks of "perfect suitability". The GFI value obtained from the analysis is close to the optimal value.

When the AGFI value is higher than 0.80 , this signifies that the model may be accepted as being in harmony with real values. The AGFI value analyzed in this study was at an acceptable level.

When the RMSEA value is between 0 and 0.05 this shows that it is at a level of ideal suitability. When the value is between 0.05 and 0.09 this shows an acceptable level of harmony (Ozdamar, 2013). The RMSEA value analyzed in this study was at an acceptable level. 
When the RMR value is lower than 0.10, this signifies that the model is acceptable and is in harmony with real data.

According to the results of the confirmatory factor analysis summarized above, it can be stated that the three-dimensional structure of the scale was verified in accordance with harmonization statistics.

Findings from the reliability analysis

To conduct the explanatory factor analysis, a Cronbach Alpha analysis was conducted that determined the level of reliability as regards establishing the internal consistency with the data obtained from 240 individuals. The Cronbach Alpha values calculated with regard to the three sub-factors of the questionnaire.

Table 6. The Results of the Cronbach Alpha Reliability Test

\begin{tabular}{ll}
\hline Items/Statements & Cronbach Alpha \\
\hline $10,11,13,16,18,27$ ve 28 (RME subcategory) & 0.82 \\
$20,21,23,24$ ve 25 (EUEME subcategory) & 0.82 \\
15,17 ve 19 (EJ subcategory) & 0.71 \\
\hline
\end{tabular}

An examination of Table 6

- The first sub-dimension (The Results of Multicultural Education [RME] had a coefficient of reliability calculated at 0.82 )

- The second sub-dimension (The Effect of Multicultural Education on Education [EUEME]) was found to have a coefficient of reliability of 0.82 )

- And the third sub-dimension (Equality and Justice First [EA] was found to have a coefficient of reliability of 0.82

Questionnaires having coefficients of reliability of between 0.70 and 0.90 are accepted as having a high reliability (Ozdamar, 2013). The subscales (in this study) possess a high degree of reliability.

At the end of these processes, the subscales on the scale and other items were then renumbered and by adding the headings and question numbers given below, the scale assumed its final version.

- The Results of Multicultural Education (RME): This included items 10, 11, 12, 13, 14, 15 and 16 according to the renumbered version

- The Effect of University Education on Multicultural Education (EUEME): This consisted of items 16, 18, 19, 20 and 21 according to the renumbered version.

- Equality and Justice (EA): This consisted of items 22, 23 and 24.

\section{Data Collection}

This study was conducted in the 2013-2014 academic year. Permission was requested from the relevant ethical committee at the Institute of Social Sciences at Yildiz Technical University with view to collecting data within this process. Within the data collection process, so as to apply the scale the items created on the www.surveey.com website were sent to students via e-mail. Throughout the data collection process, there was an attempt to reach students at the Faculty of Education, and in this context there was an attempt to make the link(s) on the scale clearly visible for students. A total of 1050 students clicked on the questionnaire, filled it in or partially completed it. At the end of the data entry completion period, on examination of the questionnaires, those completed by 83 particpants were cancelled on grounds that it was established that they had strayed outside the boundaries of the questionnaire. 967 paricipants then proceeded to participate fully in the study and the research was conducted on this number of participants. 


\section{Data Analysis}

The data obtained from the SMMEUSCE application was then uploaded to the IBM-SPSS 21 program. The total points were then recorded relating to the sub-dimensions of the sections showing the characteristics of the SMMEUSCE scale. The elements found in the subquestions of the research including gender, age, ethnic origin, the school at which they had been educated constituted the group of variable factors. In accordance with the data analysis carried out on this group, comparison tests were conducted with regard to averages and variances. However, in the comparison of averages and variations, it was necessary to decide whether parametric or non-parametric tests would be used. So as to use parametric tests, certain assumptions must be compared (Baykul, 1999; Buyukozturk, 2014; Green \& Salkind, 2008; Kalayci, 2005). These assumptions are as follows:

- The measurements relating to the variable factor in question should be obtained from a scale on the least equal interval level. The scales in behavioral sciences are of this nature. The section that shows the scale property(ies) of the SMMEUSCE study and its sub-dimensions are compared with an assumption that this is the case.

- According to the the sub-factor of the total points and average calculated (in this study, The distribution of points relating to the sub-dimensions of the Results of Multicultural Education [RME] the sub-dimensions of the Effect of University Education on Multicultural Education [EUEME] and the sub-dimensions of the Education and Justice [EJ] according to the variable factors must be normal. The assumption of normality.

- For cases where variable factors are thought to sometimes create difference and sometimes not to (such as gender), at least two independent groups should be created.

- The averages of the groups should relate to the same variable factor (e.g. perception, viewpoint, attitude).

- Samples in which average points are to be compared should be unrelated.

- The number of individuals belonging to a group should not fall below 30 (Parametric tests harbor the assumption of a large sample group).

In the context of these assumptions, it was tested whether the points obtained from the subfactors of the RME, EUEME and EA categories had been distributed normally. In order to test this, the "Kolmogorov-Smirnov Single Sample Test" was applied. The judgement as to whether the distribution in a given test is different to normal, is represented bt the $\mathrm{H}_{1}$ hypothesis (Kalayci, 2005). For this reason, at the end of analysis a statistical value of significance greater than 0.05 demonstrates normality. The Kolmogorov-Simirov single sample test is a test of conformity. This test examines the degree of conformity in a theoretical distribution using the value of a set sample (the points under examination) The cumulative frequency that may emerge according to a theoretical distribution may be compared with the observed distribution of cumulative frequency (Siegel, 1977).

Table 7. The Kolmogorov-Smirnov Normal Distribution Test Results According to the Points Obtained from the Subdimensions of the RME, EUEME and EJ

\begin{tabular}{llll}
\hline Sub Scale & N & sd & p \\
\hline Results of Multiculural Education (RME) & 967 & 967 & 0,00 \\
The Effect of University Education on Multicultural & 967 & 967 & 0,00 \\
Education (EUEME) & 967 & 967 & 0,00 \\
Equality and Justice (EJ)
\end{tabular}


On examining the test results of the KS test in table 7.

- The values of significance obtained from the RME can be seen to be significant $(\mathrm{p}<.05)$. This result highlights the fact that the points of the RME do not display a normal distribution.

- It can be observed that the values of significance obtained from the EUEME are indeed significant $(\mathrm{p}<.05)$. This result highlights the fact that the EUEME points do not display a normal distribution.

- It can be observed that the values of significance obtained from the EJ category are also significant $(\mathrm{p}<.05)$. This result, illustrates the fact that the EA points do not display a normal distribution.

As Baykul (1999), Buyukozturk (2014), Green and Salkind, (2008) and Kalayci (2005) have indicated, when carrying out comparisons in situations where the assumption of a normal distribution is to be compared, rather than parametric tests such as "the t-test for unrelated samples" or "ANOVA test for unrelated samples" it is more suitable to conduct non-parametric comparative tests such as "the Mann Whitney U Test" or "The Kruskal Wallis H Test". For this reason, in the comparison in this study, the Mann Whitney U Test and Kruskal Wallis H Test were applied.

\section{Assumptions and Limitations of the Study}

The following assumptions and limitations are made for this study. First assumption is students who participated in this study have been exposed to multicultural education and multiculturalism. Second assumption is students who participated in this study are expected to take the survey seriously and answers all items objectively. The study is limited to only undergraduate students in college of educations in both private and state universities in a city of Istanbul, Turkey. As a result, the findings may not be generalizable to all private and state universities in Turkey because of different ethnic diversity.

\section{Results}

In this section, the results from the data were analyzed and summarized.

\section{Perspective of Multicultural Education}

From the descriptive results, an arithmetical average and information concerning the average situation of the group in accordance with the characteristic being measured. In the context of the study, the SMMEUSCE was employed.

Table 8. Descriptive Statistics According to RME, EUEME, EA

\begin{tabular}{lll}
\hline & N & 967 \\
& Average $(\overline{\mathrm{x}})$ & 27,08 \\
Results of Multicultural & Standard average error $(\overline{\mathrm{x}})$ & 0,15 \\
Education (RME) & Standard deviation $(\mathrm{S})$ & 4,51 \\
& Irregularity/Deformity & $-0,73$ \\
& Flatness & 1,77 \\
& Minimum points & 7 \\
& Maximum points & 35 \\
\hline & $\mathrm{N}$ & 967 \\
& Average $(\overline{\mathrm{x}})$ & 17,77 \\
Effect of University Education on & Standard average error & 0,13 \\
Multicultural Education & Deviation (S) & 3,91 \\
(EUEME) & Irregularity/Deformity & 0,40 \\
& Flatness & 10,65 \\
& Minimum Points & 5 \\
& Maximum Points & 57 \\
\hline
\end{tabular}


Table 8. Continue

\begin{tabular}{lll}
\hline & $\mathrm{N}$ & 967 \\
& Average $(\overline{\mathrm{x}})$ & 12,77 \\
& Average Standard Error & 0,06 \\
Education and Justice (EJ) & Standard deviation(S) & 2,02 \\
& Irregularity/Deformity & $-1,02$ \\
& Flatness & 1,23 \\
& Minimum Points & 3 \\
& Maximum Points & 15 \\
\hline
\end{tabular}

On examination of Table 8;

- The average of the points for RME was stated as $27.08 / 77.37 \%)$. If it is considered that the highest score that may be taken from this sub-dimension is 35 , it can be said that positive perceptions are held (by participants) regarding multicultural education

- The average of the points for EUEME was given as 17.77 (71.08\%). If it is considered that the highest points obtainable from this subdimension is 25 , than it can be argued that there are positive perceptions held on the topic of the effect of university education on multicultural education

- The average of the EJ points is determined as 12.77 (85.13). If it is considered that the highest points obtainable from this subdimension is 15 , then it can be argued that positive perceptions are held on the topic of equality and justice.

\section{Gender-The Perception of Multicultural Education}

One of the questions asked was whether "there is a significant difference in perceptions of multicultural education according to gender". In looking for an answer to this question, on account of the fact that the points recorded from the RME, EUEME and EJ sub-dimensions did not display a normal distribution, the "Mann Whitney U Test" was used.

Table 9. Comparion of Points for RME, EUEME and EJ According to gender (The Mann Whitney U Test

\begin{tabular}{|c|c|c|c|c|c|c|}
\hline Variable Factor & Gender & $\mathbf{N}$ & $\begin{array}{l}\text { Sequence } \\
\text { Number }\end{array}$ & $\begin{array}{l}\text { Sequence } \\
\text { Total }\end{array}$ & U Value & $\mathrm{p}$ \\
\hline \multirow{2}{*}{$\begin{array}{l}\text { Results for Multicultural } \\
\text { Education (RME) }\end{array}$} & Female & 761 & 490,79 & 373492,00 & \multirow{2}{*}{73215,00} & \multirow{2}{*}{0,14} \\
\hline & Male & 206 & 458,91 & 94536,00 & & \\
\hline \multirow{2}{*}{$\begin{array}{l}\text { The Effect of University } \\
\text { Education on Multicultural } \\
\text { Education (EUEME) }\end{array}$} & Female & 761 & 495,59 & 377144,50 & \multirow[b]{2}{*}{69562,50} & \multirow[b]{2}{*}{0,01} \\
\hline & Male & 206 & 441,18 & 90883,50 & & \\
\hline \multirow{2}{*}{ Equality and Justice (EJ) } & Female & 761 & 488,56 & 371792,00 & \multirow{2}{*}{74915,00} & \multirow{2}{*}{0,32} \\
\hline & Male & 206 & 467,17 & 96236,00 & & \\
\hline
\end{tabular}

It was understood that there was no significant difference in the points for the RME and EJ subcategories $(\mathrm{U}=73215,00 ; 74915,00, \mathrm{p}>.05)$. However, in the differences between the perceptions of female and male undergraduate students, a significant difference was found $(U=69562,50, p<.05)$. This difference was in favour of female undergraduate students. This is on account of the fact that the sequence number of females is higher than that of males. Women therefore hold more positive perceptions on the topic of the effect of university education on multicultural education.

\section{Ethnic Background-Multicultural Perceptions of Education}

One of the questions of the study was whether "there is a significant difference in perceptions of multicultural education according to ethnic background. When looking for an answer to the question, the points derived from the sub-factors of the RME, EUEME and EJ did not show a normal distribution; therefore a "Kruskal Wallis H Test" was used. 
Table 10. A Comparison of RME, EUEME and EJ Points According to Ethnic Background (Kruskal Wallis H Test)

\begin{tabular}{|c|c|c|c|c|c|c|c|}
\hline Variable Factor & Ethnic Group & $\mathbf{N}$ & $\begin{array}{l}\text { Sequence } \\
\text { Average }\end{array}$ & sd & $\chi^{2}$ & $\mathrm{p}$ & $\begin{array}{l}\text { Significant } \\
\text { Difference }\end{array}$ \\
\hline \multirow{7}{*}{$\begin{array}{l}\text { The Results of Multicultural } \\
\text { Education (RME) }\end{array}$} & 1.Arab & 12 & 727,50 & & & & \multirow{7}{*}{$\begin{array}{l}3-4,1-4 \\
3-5,1-5 \\
3-7\end{array}$} \\
\hline & 2.Circassian & 13 & 570,35 & & & & \\
\hline & 3.Kurdish & 71 & 667,13 & & & & \\
\hline & 4.Laz & 28 & 422,02 & 6 & 49,41 & 0,00 & \\
\hline & 5.Turkish & 736 & 459,77 & & & & \\
\hline & 6.Zaza & 12 & 565,08 & & & & \\
\hline & 7.Other & 95 & 500,27 & & & & \\
\hline \multirow{7}{*}{$\begin{array}{l}\text { Effect of UniversityEducation } \\
\text { on Multicultural Education } \\
\text { (EUEME) }\end{array}$} & 1.Arab & 12 & 324,67 & \multirow{7}{*}{6} & \multirow{7}{*}{27,33} & \multirow{7}{*}{0,00} & \multirow{7}{*}{$3-5$} \\
\hline & 2.Circassian & 13 & 348,12 & & & & \\
\hline & 3.Kurdish & 71 & 377,57 & & & & \\
\hline & 4.Laz & 28 & 452,29 & & & & \\
\hline & 5.Turkish & 736 & 507,59 & & & & \\
\hline & 6.Zaza & 12 & 363,71 & & & & \\
\hline & 7.Other & 95 & 444,05 & & & & \\
\hline \multirow{7}{*}{ Equality and Justice (EJ) } & 1.Arab & 12 & 642,08 & \multirow{7}{*}{6} & \multirow{7}{*}{17,10} & \multirow{7}{*}{0,01} & \multirow{7}{*}{$3-4,3-5$} \\
\hline & 2.Circassian & 13 & 554,38 & & & & \\
\hline & 3.Kurdish & 71 & 569,23 & & & & \\
\hline & 4.Laz & 28 & 384,86 & & & & \\
\hline & 5.Turkish & 736 & 474,00 & & & & \\
\hline & 6.Zaza & 12 & 555,00 & & & & \\
\hline & 7.Other & 95 & 488,42 & & & & \\
\hline
\end{tabular}

In Table 10, according to the RME category, the significant difference was defined as $\left(\chi^{2}(6)=\right.$ 49,41, $\mathrm{p}<.05$ ) These differences showed that;

- Between those of a Kurdish and those of a Laz origin, the results were in favour of the Kurdish group,

- Between those of an Arab origin and a Laz origin, the results were in favour of the Arab group,

- Between those of a Kurdish origin and those of a Turkish origin, the results were in favour of the Turkish group,

- Between those of an Arab origin and those of a Turkish origin, the results were in favour of the Arab group,

- Between those of a Kurdish origin and those of other ethnic groups, there is a significant difference in favour of the Kurdish group.

Those of an Arab and Kurdish ethnic origin can therefore be said to possess more positive perceptions as regards the results of to multicultural education.

In table 10, it was established that there is a significant difference in regard to ethnic origin with respect to the EUEME subcategory $\left(\chi^{2}(6)=27,33, p<.05\right)$.

- Between those of a Kurdish and those of a Turkish ethnic origin, A significant difference is therefore indicated in favour of the Turkish group.

It is established from these results that those of a Turkish ethnic background have a more positive perception of the effect of university education on multicultural education than those of a Kurdish ethnic origin. 
In Table 10, a significant difference was established with regard to ethnic origin cocnerning the EJ category. These differences demonstrated $\left(\chi^{2}(6)=17,10, p<.05\right)$.

- Between those of a Kurdish and those of a Laz ethnic background, the difference was in favour of the Kurdish group.

- Among those of a Kurdish and those of a Turkish ethnic background, the difference was in favour of the Kurdish group.

Therefore, it was established that those of a Kurdish ethnic background harbour more positive perceptions than those of a Turkish or Laz background on the subject of equality and justice.

Type of University (Private/State)- The Perception of Multicultural Education

One of the research questions was that of whether "there is a significant difference in perceptions of multicultural education according to the school that undergraduate students have attended." On account of the fact that a normal distribution of points was not recorded for the RME, EUEME and EA subcategories, the "Mann Whitney U Test" was used.

Table 11. A Comparison of RME, EUEME and EJ Scores According to Educational Institution Attended

\begin{tabular}{lllllll}
\hline Variable Factor & $\begin{array}{l}\text { Type of } \\
\text { Institution }\end{array}$ & $\mathbf{N}$ & $\begin{array}{l}\text { Sequence } \\
\text { Average }\end{array}$ & $\begin{array}{l}\text { Sequence } \\
\text { Total }\end{array}$ & U Value & $\mathbf{p}$ \\
\hline The Results of Multicultural & Private univ. & 350 & 512,05 & 179217,50 & $\mathbf{9 8 1 5 7 , 5 0}$ & $\mathbf{0 , 0 2}$ \\
Education (RME) & State univ. & 617 & 468,09 & 288810,50 & & \\
The Effect of University & Private univ. & 350 & 559,09 & 195682,00 & $\mathbf{8 1 6 9 3 , 0 0}$ & $\mathbf{0 , 0 0}$ \\
Education on Multicultural & & & & & & \\
Education (EUEME) & State univ. & 617 & 441,40 & 272346,00 & & \\
Education and Justice (EJ) & Private univ. & 350 & 443,69 & 155293,00 & $\mathbf{9 3 8 6 8 , 0 0}$ & $\mathbf{0 , 0 0}$ \\
\hline & State univ. & 617 & 506,86 & 312735,00 & & \\
\hline
\end{tabular}

According to table 11, it can be understood that there exists a significant difference between the scores obtained for undergraduate students at state and private universities according to the RME, EUEME and EJ subcategories $(\mathrm{U}=\mathbf{9 8 1 5 7 , 5 0 ; 8 1 6 9 3 , 0 0 ; 9 3 8 6 8 , 0 0} \mathrm{p}>.05)$. The RME, EUEME and EJ categories all show a significant difference in favour of the state university. Therefore, students at state universities harbor perceptions on the subjects of multicultural education, the effect of university education on multicultural education and equality and justice.

\section{Discussion and Conclusion}

Over recent years, the concept of multicultural education and discussions concerning it have assumed a great importance as cultures have increasingly interacted (in our contemporary age). In this regard, significant research has been conducted; states have also at steady intervals carried out legal reforms with regard to the issue. In this study, the opinions of teacher candidates who will become the teachers of the future with regard to the topic of multicultural education were examined. In this context, answers to question such as the following were sought: "how to understand multicultural education", "how does this concept take shape in the mind" and "what is the effect of life at university on this situation?"

Within the context of this study, a Scale of the Multicultural Education of Undergraduate Students at College of Education (SMMEUSCE) was employed. The subcategories of the SMMEUSCE are "the Results of Multicultural Education (RME)", "the Effect of University Education on Multicultural Education (EUEME)" and "Equality and Justice (EJ)." On examination of the points for the RME category, it can be seen that the highest obtainable score is 35 points. According to these results, it can be maintained that positive perceptions were held by the participants with regard to the topic of multicultural education. The average score from the EUEME was $17.77(71.08 \%)$. When a score is 
detected that is higher than 25 , it can be asserted that there exist positive perceptions as regards the effect of university education on university education. The average EJ score was 12.77 (85.13\%). If we consider that the highest score possible for this category is 15 , it can be established that there is a positive perception as regards the topic of equality and justice.

For the perception regarding gender and multicultural education, on account of the fact that the points obtained for the RME, EUEME and EJ subcategories did not display a normal distribution, a "Mann Whitney U Test" was employed. At the end of the data analysis conducted, it was observed that there was no significant difference with regard to the RME and EJ subcategories. However, in the EUEME subcategory, a significant difference was observed between the perceptions of female and male undergraduate students. This difference was in favor of women. In other words, women are of the view that university education had a positive effect on multicultural education. Tortop (2014) found a similar result regarding the RME in his study. According to the results of this study, it was established that no differences in multicultural educational attitudes were demonstrated with regard to gender. In many other studies on the same subject, it was found that that the RME displayed no differences with regard to gender (Yazici, Basol, \& Toprak, 2009; Ozdemir \& Dil, 2013).

For another one of the questions, "Is there a difference in viewpoints towards multicultural education with regard to the way that the participant defines himself or herself in terms of ethnic identity?", the question was observed from three subcategories. As the scores obtained from this category did not demonstrate a normal distribution, a "Kruksal Wallis Test" was employed. As a result of the analysis of the data, when the subcategories of the RME were examined, those participants of Arab and Kurdish backgrounds were found to possess more positive perceptions on the topic of multicultural education than those of other ethnic origins. On consideration of the EUEME subcategory, those participants of a Turkish ethnic background were found to have a more positive perception than those of a Kurdish ethnic origin. Examining the EJ subcategories, it was determined that participants of a Kurdish ethnic background were discovered to hold more positive perceptions than those of a Turkish or Laz ethnic origin. This situation demonstrates in a clear manner how Turks, who represent the most populous group in Turkey have noticed the difference between university education and multicultural education, and this is the group that has undergone the greatest changes in its thoughts and attitudes. Sharma (2005), in a similar study, researched perceptions of high school teachers towards multicultural education. In his study, that employed both qualitative and quantitative methods, questions in a survey form were sent to 150 teachers chosen at random and face-to-face interviews were conducted with 15 teachers. In the findings that emerged, a low correlation was established between demographic information and perceptions. However, this study shows us that, for those who will undertake teaching in places in which there is cultural diversity, an effective preparation for multicultural education is necessary. Every year, on account of the increase in cultural diversity, the need for teachers who are sensitive to cultural diversity increases steadily. Nevertheless, in another study concerning the nature of the ethnic composition of Turkey, to the statement of "I feel free and equal in this country"; $28.9 \%$ answered "I agree", 18.6\% replied that "I definitely not agree", 20.9\% responded "I disagree" and 23.9\% "I definitely disagree" (UKAM, 2013b).

Another one of the questions was phrased as follows: "Is there a difference in the views of private and state university students towards multicultural education". Here the types of university (private and state) were compared. On account of the fact that the distribution of the points was not considered normal, a "Mann Whitney U Test" was used. On completion of the data analysis, it was determined that there existed a significant difference in the RME, EUEME and EJ subcategories. This difference was in favor of state universities; that is to say that in all three categories, participants from state universities held more positive perceptions. This situation may be interpreted by the fact that state universities have a more cosmopolitan make-up and originate from the fact that they encompass students from different sections of society. In Maatta's study (2008) of becoming acquainted with other cultures and teaching in such environments, the competency of teachers with regard to students from other cultures was examined. In this context, differentiating factors such as gender, age, teaching 
experience, experience of migrant education were considered. Among these variable factors, the most important factor that affected teacher competence was that of experience of teaching within different cultures. The study reached the conclusion that these teachers with this kind of experience felt more at ease in the classroom. Variables such as age and teaching experiences were discovered as not constituting a significant difference for multicultural education. These teachers connected with the multicultural experiences they had enjoyed and with the materials developed in connection with this topic. It emerged from the study that teachers had to be more sensitive with regard to students belonging to different cultural groups and that teachers needed to be trained in an appropriate way for the needs of multicultural education.

When questions were asked regarding perceptions of multicultural education and department attended, it was established that the points of the subcategories were not distributed in a normal fashion and so the "Kruskal Wallis H Test" was used. After the data analysis stage was conducted, it was determined that students at the Pre-school Teaching, Humanities Teaching and Foreign Teaching and Foreign Languages Teaching Departments had more positive perceptions than those at the Science Teaching Department as regards the topic of the results of multicultural education. In the subcategory of EUEME, it was ascertained that there existed a significant difference. This difference manifested itself in the sense that Pre-School Education students harbored more positive perceptions with regard to the effect of university education on Computer Education and Instructional Technologies (CEIT). There was also a significant difference for the other subcategory, namely EJ. In this subcategory, Humanities students were found to hold more positive perceptions than those in the Computer and Teaching Technologies Department, the Science Teaching Department, Primary Mathematics Teaching Department, the Pre-school Teaching Department, Psychological Counseling and Guidance, other subjects, Religious Culture and Moral Instruction, Elementary Class Teaching and Turkish Teaching with regard to the topic of equality and justice. Furthermore, students at the Foreign Languages Teaching Department held more positive perceptions on the subject of equality and justice than those at the Pre-School Teaching Department.

In a similar study, it was examined whether the views of teachers towards multicultural education in the province of Tokat were affected by factors such as gender, seniority, branch (department), the faculty they had graduated from, the level at which they taught (within primary school) and the province and district in which they worked; a number of significant differences emerged. It was established that the branch, seniority, university attended and the environment in which education was conducted all exerted an influence on the attitudes of the teachers who participated in the study. It was understood on examination of the general results, that teachers held positive attitudes towards multicultural education. It was established that those teachers who had the least awareness of multicultural education, described their students with words like "the same", "or without difference". This situation was evaluated as being evidence of a need for teachers to be informed on the topic of multicultural education (Yazici et al., 2009). In contrast, in a study conducted by Tortop (2014), a significant difference was not discovered in attitudes towards multicultural education according to departments. This situation may be interpreted in light of the fact that the study that was conducted in Istanbul highlighted the cosmopolitan make-up of the city and that the diversity highlighted in the study emanate from this fact.

When one examines other studies conducted both in Turkey and internationally, it can be observed that many studies have been undertaken on the topic of multicultural education.The studies conducted have focused on a number of different aspects such as students, teachers, parents, school administrators, academicians, educational programs and educational policies. This study deals with those who have not yet become teachers; however, it was conducted using undergraduate students at the Faculty of Education who represent a group who are likely to become teachers in future years.

Basbay and Bektas (2009) in the context of their study considered teachers' sensitivity to culture, competencies and the component parts that make up these competencies. They also analyzed how these competencies shape teachers' behaviors. The study emphasized the fact that teachers are included in 
the group of professions that provide a service and this necessitates their being sensitive to other cultural values. This sensitivity is emphasized as being a multicultural competency that is based on awareness, knowledge and skills. In addition, through the creation of a multicultural learning and teaching environment, students remain attached to an environment that reflects their own values within the classroom setting. It was emphasized that the most important contribution in assisting teacher candidates in the creation of such an environment is the education that they receive while at university. The point was also stressed that during this period teacher candidates take the academicians responsible for delivering their education as role models, and that the most important contribution to be made to the attainment of multicultural competence, is the necessity of inclusion of applications that allow for the observation and evaluation of multicultural educational activities. In this context, attention was focused on the fact that at college of education the real educators are the instructors who provide educational training. Moreover, reform of the teaching program and the creation of classroom environments that allow everyone to express their culture clearly were taken as the indispensable elements of multicultural education.

Celi (2015) in his study, demonstrated that the average for democratic perceptions was 26.55. Furthermore, in this study, the perceptions with regard to multicultural education and perceptions of democracy were high. Gunay and Aydin (2015) in their conduct analysis study examined 32 academic studies and 7 books. These studies were evaluated according to a internal analysis codification method. The history of studies conducted on the area of multicultural education in Turkey dates back 10 years, reaches a peak of intensity around 2009 and in general are found to employ questionnaires regarding attitudes. It was emphasized that the studies focused on sample sizes of between 101 and 300 people, consisting predominantly of students and academicians. It can be observed that the ANOVA analysis method was employed incorporating percentage and frequency tables.

If we look once again at the definition of multicultural education; multicultural education is an expression of different identities living together in the same place (Akdemir, 2004). This process does not attach excessive importance to students' differences and is a process than ensures the continuation of education in an egalitarian environment. When the categories that emerged from the study are examined, the results of the subcategory for multicultural education were positive at a rate of $77.37 \%$, the figure regarding multicultural education was $71.08 \%$ positive while finally the subcategory of equality and justice was positive to a figure of $85.13 \%$. We can interpret this situation as demonstrating that undergraduate students at the faculty of education held positive views regarding multiculturalism and multicultural.

\section{Contribution:}

This paper is produced from first author's Master's Thesis. 


\section{References}

Akdemir, A. M. (2004). Kureselleşme ve kulturel kimlik sorunu. Atatürk Üniversitesi Sosyal Bilimler Enstitüsü Dergisi, 3(1), 43-50.

Aydin, H. (2012). Multicultural education curriculum development in Turkey. Mediterranean Journal of Social Sciences, 3(3), 247-263.

Aydin, H. (2013a). A literature-based approaches on multicultural education. Anthropologist, 16(1-2), 3144.

Aydin, H. (2013b). Çokkültürlü Ĕ̆itime Giriş (5th ed.). Ankara: Anı Akademi Yayıncılık.

Aydin, H., \& Tonbuloglu, B. (2014). Graduate students perceptions' on multicultural education: A qualitative case study. Eurasian Journal of Educational Research, 57, 29-50.

Banks, J. A. (1995). Multicultural education: Historical development, dimensions, and practice. In J. A. Banks, \& C. A. McGee Banks (Eds.), Handbook of research on multicultural education (pp. 3-24). New York, NY: Simon \& Schuster.

Banks, J. A. (1999). An Introduction to Multicultural Education (2nd ed.). Boston, MA: Allyn and Bacon Press.

Banks, J. A. (2004a). Multicultural education: characteristics and goals. In J. Banks, \& C. Banks (Eds.), Multicultural education: Issues and perspectives (pp. 3-30). San Francisco, CA: Jossey-Bass.

Banks, J. A. (2004b). Teaching for social justice, diversity, and citizenship in a global world. The Educational Forum, 68, 289- 298. doi:10.1080/00131720408984645

Banks, J. A. (2008). An introduction to multicultural education (4th ed.). Boston, MA: Allyn \& Bacon.

Banks, J. A., \& Banks, C. A. M. (2013). Multicultural education: Issues and perspectives (8th ed.). Hoboken, NJ: John Wiley \& Sons.

Basbay, A., \& Bektas, Y. (2009). Instructional environment and teacher competences in the context of multiculturalism. Egitim ve Bilim, 34(152), 30-43.

Baykul, Y. (1999). İstatistik metodlar ve uygulamalar. Ankara: Anı Yayıncılık.

Bennett, C. (1995). Comprehensive multicultural education: Theory and practice (3rd ed.). Cambridge, MA: Allen \& Bacon.

Brown, M. R. (2007). Educating All Students: Creating Culturally Responsive Teachers, Classrooms, and Schools. Intervention in School and Clinic, 43(1), 57-62. doi:10.1177/10534512070430010801

Bulut, Y. (2015). Multiculturalism and education: Contemporary issues in education studies (Book Review). Journal of Ethnic and Cultural Studies, 2(1), 55-57.

Buyukozturk, S. (2003). Sosyal Bilimler İçin Veri Analizi El Kitabı. Ankara: Pegem Yayıncılık.

Buyukozturk, S. (2014). Sosyal Bilimler İçin Veri Analizi El Kitabı (19th ed.). Ankara: Pegem Yayıncılık.

Buyukozturk, S., Kilic Cakmak, E., Akgun, O. E., Karadeniz, S., \& Demirel, F. (2014). Bilimsel Araştırma Yöntemleri. Ankara: Pegem Akademi.

Celi, S. (2015). Multicultural Education And Democracy Perceptions Of Undergraduate Students In Turkey: Kirikkale University And Yildiz Technical University Sample (Unpublished masters' thesis). Yildiz Technical University, İstanbul.

Cirik, I. (2008). Multicultural education and its reflections. Hacettepe Üniversitesi Ĕ̆itim Fakültesi Dergisi, $34,27-40$.

Cotok, A. N. (2010). Çokkültürlülük, kültürlerarasılık ve entegrasyon tartışmaları bağlamında Alman eğitiminde Türk öğrenciler: Bremen örneği (Unpublished doctoral dissertation). Sakarya University, Institute of Social Science, Sakarya.

Ergil, D. (1995). Çokkültürlülük ve çok dillilik [Multiculturalism and Multilingualism]. Ankara Üniversitesi Siyasal Bilgiler Dergisi, 50(3), 159-165. 
Faltis, C. (2014). Toward a race radical vision of bilingual education for Kurdish users in Turkey: A commentary. Journal of Ethnic and Cultural Studies, 1(1), 1-5.

Gay, G. (1994). A synthesis of scholarship in multicultural education. Retrieved from ERIC databases (ED378287)

Gay, G. (2002). Preparing for culturally responsive teaching. Journal of Teacher Education, 53(2) 106-116. doi:10.1177/0022487102053002003

Gay, G. (2004). Curriculum theory and multicultural education. In J.A. Banks, \& C.A.M. Banks (Eds), Handbook of research on multicultural education (pp. 30-49). San Francisco, CA: Jossey-Bass.

Glassman, R. M., Swatos, W. H. Jr., \& Denison, B. J. (2004). Social Problems in Global Perspective. Lanham, MD: University Press of America.

Glazer, N. (1997). We are all Multiculturalists Now. Cambridge, MA: Harvard University Press.

Gorski, P. (2006). Complicity with conservatism: the do-politicizing of multicultural and intercultural education. Intercultural Education, 17(2), 163-177. doi:10.1080/14675980600693830

Grant, C., \& Sleeter, C. (2006). Turning on learning: Five approaches to multicultural teaching plans for race, class, gender, and disability. Upper Saddle River, NJ: Prentice-Hall.

Green, S. B., \& Salkind, N. J. (2008). Using SPSS for Windows and Macintosh: Analyzing and understanding data (5th ed.). Upper Saddle River, NJ: Pearson/Prentice Hall.

Gunay, R., \& Aydin, H. (2015). Inclinations in studies into multicultural education in Turkey: A content analysis study. Egitim ve Bilim-Education and Science, 40(178), 1-22.

Joreskog, K. G., \& Sorbom, D. (1993). Lisrel 8: Structural Equation Modeling With the Simplis Command Language. Chicago: Erlbaum Associates Publishers.

Karatas, K., \& Oral, B. (2015). Teachers' perceptions on culturally responsiveness in education. Journal of Ethnic and Cultural Studies, 2(2), 47-57.

Kalayci, S. (2005). SPSS Uygulamali Çok Degiskenli Istatistik Teknikleri (4th ed.). Ankara: Asil Publication. Kaya, I. (2007). Azinliklar, Çokkültürlülük ve Mardin. D.Ü.Ziya Gökalp Eğitim Fakültesi Dergisi 9, 44-55.

Kaya, D. (2014). Multiculturalism and education: Contemporary issues in education studies (Book Review). Journal of Ethnic and Cultural Studies, 1(1), 38-39.

Kaya, Y. (2015). The opinions of primary school, Turkish language and social science teachers regarding education in the mother tongue (Kurdish). Journal of Ethnic and Cultural Studies, 2(2), 33-46.

Kaya, I., \& Aydin, H. (2014). Çoğulculuk, Çokkültürlü ve Çokdilli Eğitim [Pluralism, Multicultural, and Multilingual Education]. Ankara: Anı Yayınc1lık.

Kitano, M. K. (1997). What a course will look like after multicultural change. In A. I. Morey, \& M. K. Kitano (Eds.), Multicultural course transformation in higher education: A broader truth (pp. 18-34). Boston : Allyn Bacon.

Kline, R. B. (2005). Principles and Practice of Structural Equation Modeling. NewYork: The Guilford Press.

Kridel, C. (Ed.). (2010). Encyclopedia of Curriculum Studies. Thousand Oaks, CA: SagePublication, Inc. doi:10.4135/9781412958806

Lafer, S. (2014). Democratic design for the humanization of education. Journal of Ethnic and Cultural Studies, 1(1), 6-12.

Maatta, S. (2008). Experience Matters: Teacher Perceptions of Multicultural Education and Their Competence to Teach from Different Cultural Backgrounds (Master's thesis). University of Jyvaskalya, Department of Educational Studies, Finland.

Nieto, S. (2004). Affirming diversity: The sociopolitical context of multicultural education. New York, NY: Longman.

Ozdamar, K. (2013). Paket Programlar ile İstatistiksel Veri Analizi (9th ed., Vols. 1-2). Eskis,ehir: Nisan Kitabevi. 
Ozdemir, M., \& Dil, K. (2013). Teachers' attitudes toward multicultural education: Case of Çankiri province. Egitim Bilimleri Fakultesi Dergisi, 46(2), 215.

Parekh, B. (2002). Çokkültürlülü̈̆̈̈ Yeniden Düşünmek, Kültürel Çeşitlilik ve Siyasi Teori [Rethinking Multiculturalism-Cultural Diversity and Political Theory] (B. Tanrıseven, Trans.). Ankara: Phoenix Yayınevi.

Polat, I., \& Kilic, E. (2013). Multicultural education in Turkey and teachers' competencies in multicultural education. YYü Ĕ̆itim Fakültesi Dergisi, 5(1), 352-372.

Schmitz, B. (1999). Transforming a course. CIDR Teaching and Learning Bulletin, 2(4), 1-2.

Sharma, S. (2005). Multicultural education: teachers' perceptions and preparation. Journal of College Teaching and Learning, 2(5), 53-63.

Siegel, S. (1977). Davranıs bilimleri için parametrik olmayan istatistikler [Nonparametric statistics for the behavioral sciences] (Y. Topsever, Trans.). Ankara: Ankara Üniversitesi Dil ve Tarih-Coğrafya Fakültesi Yayınları.

Sleeter, C. (1996). Multicultural education as social activism. Albany, NY: State University of New York Press.

Sonmez, V., \& Alacapınar, F. G. (2011). Örneklendirilmiş Bilimsel Araştırma Yöntemleri. Ankara: Anı Yayıncilik.

Sumer, N. (2000). Structural equation modelling: Basic concepts and applications. Turkish Psychological Articles, 3(6), 49-74.

Tortop, H. S. (2014). Attitudes of candidate teachers towards multicultural and gifted education. Journal of Gifted Education Research, 2(2), 16-26.

UKAM. (2013a). The Question of Mother Tongue Education in Turkey: Challenges, Experiences, and Model Recommendations for Bilingual. İstanbul: UKAM Yayınları.

UKAM. (2013b). Public Perceptions on Kurdish Question and Solution Process. Istanbul: UKAM Yayınları.

Woods, D. R. (2009). High School Students' Perceptions of the Inclusion of Multicultural Education in a Suburban School District (Unpublished dissertation). Wayne State University, Detroit, Michigan.

Yazici, S., Basol, G., \& Toprak, G. (2009). Teachers' attitudes toward multicultural education: A study of relaibility and validity. Hacettepe Üniversitesi Ĕ̆itim Fakültesi Dergisi (HU Journal of Education), $37,229-242$. 